\title{
SEISMIC ACTIVITY INDUCED BY WATER INJECTION AT MATSUSHIRO, JAPAN
}

\author{
Masakazu Oнтаке \\ International Institute of Seismology and Earthquake Engineering, \\ Tokyo, Japan
}

(Received February 27, 1974; Revised April 15, 1974)

\begin{abstract}
City water, amounting $2883 \mathrm{~m}^{3}$, was pumped into a well of $1800 \mathrm{~m}$ deep at Matsushiro, central Japan. The pumping pressure was 50 to 14 bars. Several days after the start of the fluid injection, a series of microearthquakes commenced two to four kilometers away from the well. Detailed investigations of those earthquakes confirmed that the unusual seismic activity was triggered by the water injection. Most of the supplied water seems to have permeated through the Matsushiro earthquake fault. Intrinsic permeability of the fault zone was estimated as 0.01-0.1 darcy, which are reasonable values for fractured rocks.
\end{abstract}

\section{Introduction}

For the purpose of examining whether earthquakes could be induced by increase of pore water pressure, a water pumping into a deep well was carried out at Matsushiro, central Japan, from January to February of 1970 . Seismicity of the Matsushiro area was monitored with highly sensitive seismographs installed at several observation points including one tripartite station. Based on the seismological data, we studied on time and space distribution of earthquakes and their fault-plane solutions. Permeability through the Matsushiro earthquake fault was also investigated. All the results were consistent with the pore pressure hypothesis of earthquake occurrence that increases in pore water pressure reduce the strength of the rocks and result in premature releases of elastic stress.

The importance of pore fluid pressure in occurrence of shallow earthquakes was, for the first time, demonstrated in the case of the Denver, Colorado, earthquakes started in 1962. Elaborate studies by HollisTer and Weimer (1968) and Healy et al. (1968) confirmed the foresight of Evans (1966), that those shocks were induce by fluid injection into a deep disposal well since 1962. Similar relations between local seismicity and fluid injection were found at the Rangely Oil Field, Colorado, by PAKISER et al. (1969), HEALY et al. (1972) and GrBBs et al. (1973), and in the Los Angeles basin area by Teng et al. (1973). Those recent studies in the United States have been 
carried out taking advantage of massive water flooding and oil production at oil fields. Water injection at Matsushiro, on the contrary, was operated for purely scientific purpose from beginning to end, and we could put into practice a well-planned monitoring of local seismicity.

Summarizing seismic activities associated with filling of large artificial reservoirs, RотнÉ (1970) suggested that those activities might be triggered by increases in interstitial water pressure in the rocks beneath the reservoirs.

The concept that pore pressure may reduce the strength of rocks was first proposed by HUBBERT and RUBEY (1959) and was developed through laboratory experiments (for instance, BRACE, 1972). The results of those field observations and laboratory studies played an important role in recent development of the dilatancy model for earthquake occurrence (NuR, 1972).

\section{Field Experiment}

National Research Center for Disaster Prevension drilled a deep well of $1800 \mathrm{~m}$ in depth nearly on the Matsushiro earthquake fault which was formed during the Matsushiro swarm earthquakes started in August of 1965. The total length of the borehole was as long as $1934 \mathrm{~m}$ because of its considerable curving affected by geological conditions of the stratum. Its diameter was $7 \frac{5}{8}$ inches at the top and $64 \mathrm{~mm}$ at the bottom of the well.

City water was pumped into this well in two periods. The first injection started on January 15, 1970 and was succeeded for three days. A pressure of 50 bars was given to pump the water totalling $32.4 \mathrm{~m}^{3}$ into the well. The water was supplied to the medium deeper than $1334 \mathrm{~m}$ because the shallower part of the well was protected by steel casing. After an interruption of a dozen of days, the second injection started on January 31. The casing beneath the depth of $1072 \mathrm{~m}$ was removed this time. At the beginning, a pressure of 23 bars was necessary to inject the water at the rate of 120 liter $/ \mathrm{min}$. A small pressure of 14 bars, however, was found to be sufficient on the third day and afterwards to keep the rate of water supply constant. On February 6, the pumping machine was replaced by a more powerful one in order to raise the injection rate, and water supply of 200-300 liter/min was succeeded under a pressure of 14-20 bars till February 13 . The total amount of water supply was $2850.6 \mathrm{~m}^{3}$ for the second injection.

Hokushin Microearthquake Observatory and its satellite stations had been monitoring the seismicity of the northern part of Nagano Prefecture including the Matsushiro area. In order to supplement this observing net, we temporarily installed a tripartite station at Hoshina (HS), five kilometers away from the well. Seismic signals from three vertical seismographs set up at apexes of a triangle with sides of $789 \mathrm{~m}, 995 \mathrm{~m}$ and $1100 \mathrm{~m}$ and two harizontal 


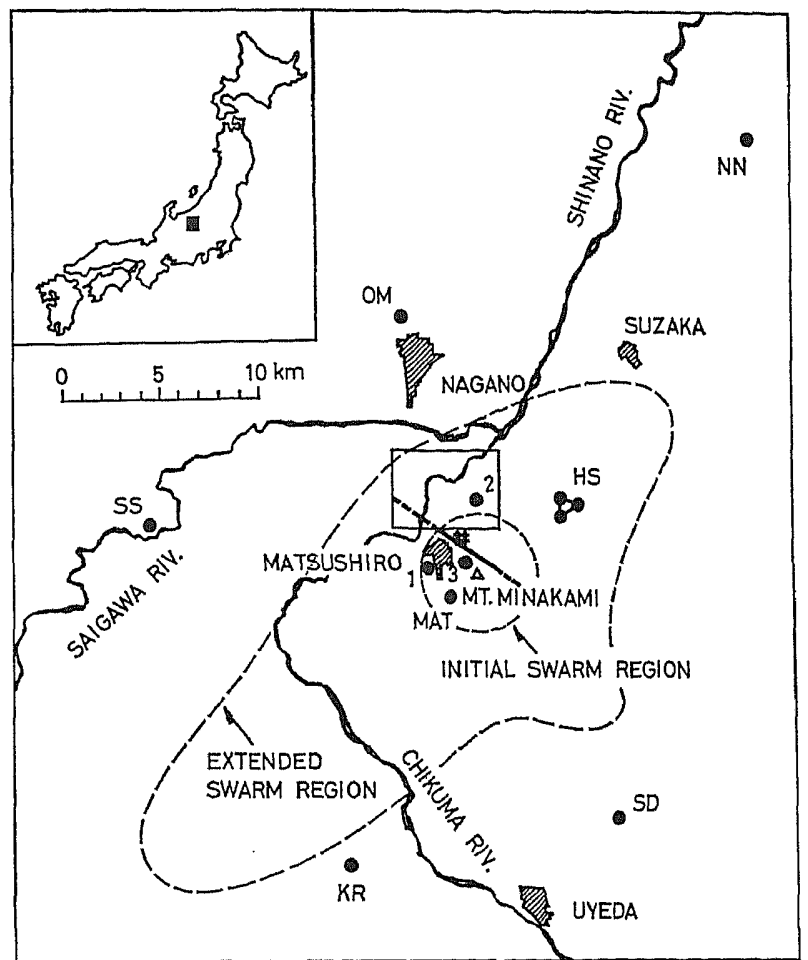

Fig. 1. Index map of the northern part of Nagano Prefecture. Thick line: Matsushiro earthquake fault. Parallel crosses: Boring site. Solid circles: Seismograph stations (HS, Hoshina tripartite station; MAT, permanent station of the Japan Meteorological Agency; 1-3, temporary stations of the National Research Center for Disaster Prevention; the others, stations of the Hokushin Microearthquake Observatory). A rectangle to the north of Matushiro Town indicates the area of water effect in which seismicity was minutely investigated. The initial and the extended swarm region of the Matsushiro earthquakes are bounded by broken curves.

seismographs at the main point were continuously recorded on magnetic tapes through a six-channel data recorder. The sixth channel was used for time signals. The seismograms were later reproduced on paper with a speed of $25 \mathrm{~mm} / \mathrm{sec}$. Time differences in $\mathrm{P}$ arrivals of the three vertical seismograms and S-P intervals were read to $0.1 \mathrm{~mm}(4 \mathrm{msec})$ for precise determination of hypocenters. Overall magnification of the system was about $2 \times 10^{5}$ at $10 \mathrm{~Hz}$.

Local seismicity during the period of the experiment was also monitored by a permanent station of Japan Meteorological Agency at Matsushiro, and three temporary stations of the National Research Center for Disaster Prevention. Location of the seismograph stations and the boring site is summarized in Fig. 1. 


\section{Geological Conditions beneath the Boring Site}

Matsushiro and its neighbouring towns and villages had been shaken by the Matsushiro swarm earthquakes since August of 1965. On April 17 of the following year, the maximum number of 661 shocks in one day was felt at Matsushiro Town. Although the epicenters were initially restricted to around Mt. Minakami, a tertiary volcano, the swarm region gradually spread out selectively in northeastern and southwestern directions until it attained an ellipse with a major and minor axes of $34 \mathrm{~km}$ and $18 \mathrm{~km}$ in 1967 (HAGIWARA and IWATA, 1968).

Seismic activity near the boring site for the present experiment was especially violent at the early stage of the swarm. It turned to a remarkable decay in the autumn of 1966 in contrast with considerable activities at other places in the extended swarm region. HAGIWARA and IWATA (1968) con-
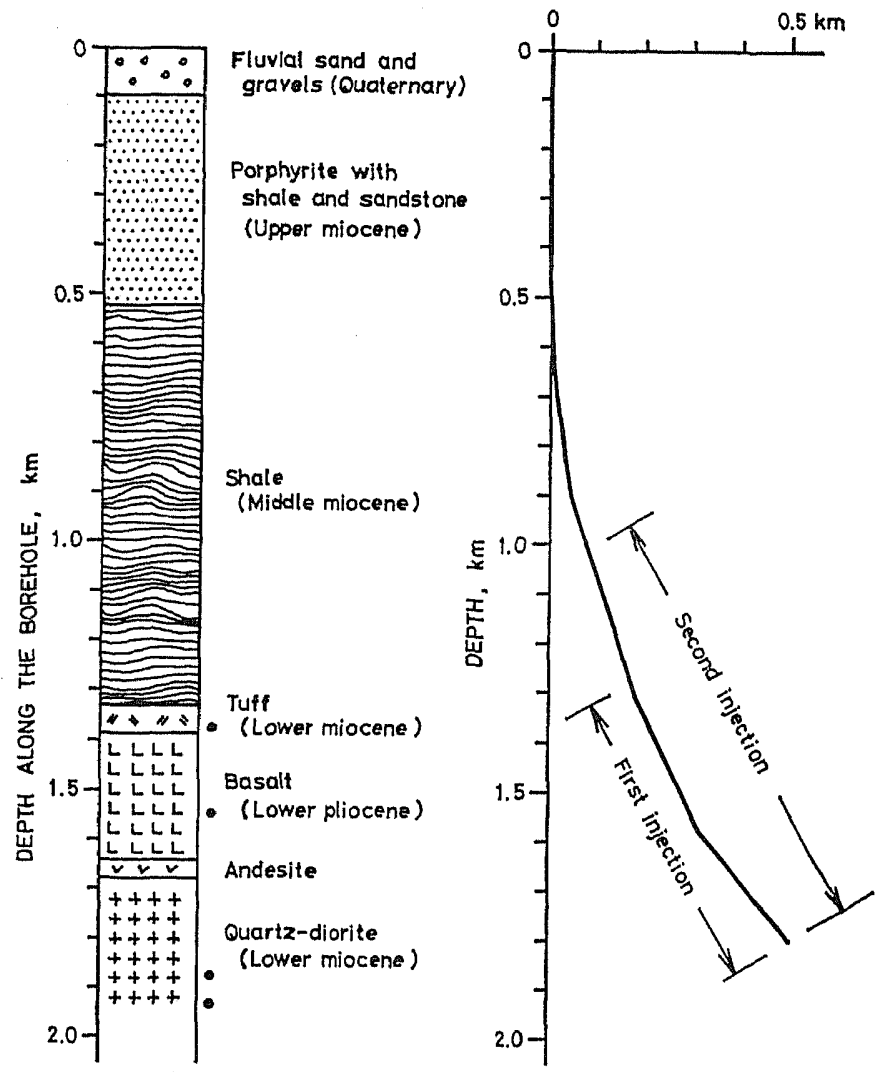

Fig. 2. Geological section of the strata beneath the boring site (left), and the vertical profile of the borehole (right). Small solid circles indicate the location of fresh slicken sides. 
sidered that the medium concerned had been completely fractured and it could no longer store elastic energy. This idea was supported by the fact that a series of ground cracks en echelon developed on the northeastern side of Mt. Minakami from the spring to the autumn of 1966. NaKamura and TSUNEISHI $(1966,1967)$ concluded that those cracks were caused by a leftlateral movement of a newly created fault in the bed rock, the Matsushiro earthquake fault. The strike of the burried fault was estimated to be N55 $\mathrm{W}$.

The deep well for the fluid injection was located nearly on the northeastern side of the fault as shown in Fig. 1. Depth of the shallowest Matsushiro earthquakes was about $1.5 \mathrm{~km}$ at that site, and the deep well was expected to penetrate into the layer in which the earthquakes did repeatedly occur. TAKAHASHI (1970) reported that fresh slicken sides were found in the core samples from the borehole deeper than $1363 \mathrm{~m}$. Such slicken sides are considered to be the scars of the Matsushiro earthquakes.

Figure 2 illustrates the geological section evaluated from core samples by TAKAHASHI $(1969,1970)$. Laboratory and in situ measurement of velocity of sonic waves revealed that the volcanic rocks beneath $1386 \mathrm{~m}$ in depth correspond to the basement layer with a longitudinal wave velocity of $6.0 \mathrm{~km} / \mathrm{sec}$ which was confirmed by Asano et al. (1969) through explosion seismic studies.

Curved shape of the borehole is also illustrated in Fig. 2. The direction of the drilling gradually deviated from the vertical, and the bottom of the completed well was horizontally $500 \mathrm{~m}$ away from the drilling site to $\mathrm{S} 22^{\circ} \mathrm{E}$. It is most probable that the bore encountered with the fault at the depth of about $600 \mathrm{~m}$ and was guided by the fault plane afterwards. The Matsushiro earthquake fault, therefore, seems to be dipped to northeast.

\section{Seismic Activity Associated with the Water Injection}

Local seismicity in the Matsushiro area was investigated in detail for the period of four months from December of 1969 through March of 1970. Although the activity of the Matsushiro swarm earthquakes was much declined at that time in comparison with the most active stages, about 20 shocks were still felt every month. Most of those shocks, however, were located in the extended swarm region outside Matsushiro Town, and the initial swarm region including the present boring site was practically aseismic.

At $02^{\mathrm{h}} 08^{\mathrm{m}}$ on January 25 (JST), that was 9.3 days since the start of the first injection, a series of microearthquakes commenced in the area under monitoring. Precise determination of the hypocenters revealed that they were clustering near the northwestern end of the Matsushiro earthquake fault, 2 to $4 \mathrm{~km}$ distant from the experiment well. During the observation, seismic activity in a rectangle area shown in Fig. 1 was rather high and was sensi- 
tively affected by the water injection. On the contrary, seismicity just beneath the well and the southeastern part of the fault kept very low level throughout the period of our observation. The following discussions are focused on the small rectangle area with $5.5 \mathrm{~km}$ in east-west and $4.0 \mathrm{~km}$ in north-south, which we tentatively call the area of water effect.

\subsection{Daily number of earthquakes}

Daily number of the shocks which occurred in the area of water effect is illustrated in Fig. 3, in which daily variations of pumping pressure, amount of the water supply and precipitation are given for comparison. An unusual seismic activity commenced on January 25 including a felt shock with magnitude 2.8 after the formula WATANABE (1971). The commencement of this seismic activity corresponds to 9.3 days after the first water supply which began on January 15. Daily number of shocks again increased on February 6 , that was 6.2 days since the start of the second injection. Another increase of daily number on February 11 occurred 4.8 days after the restart of injection with a more powerful pumping machine.

All the three largest peaks of seismic activity are correlated to the abrupt

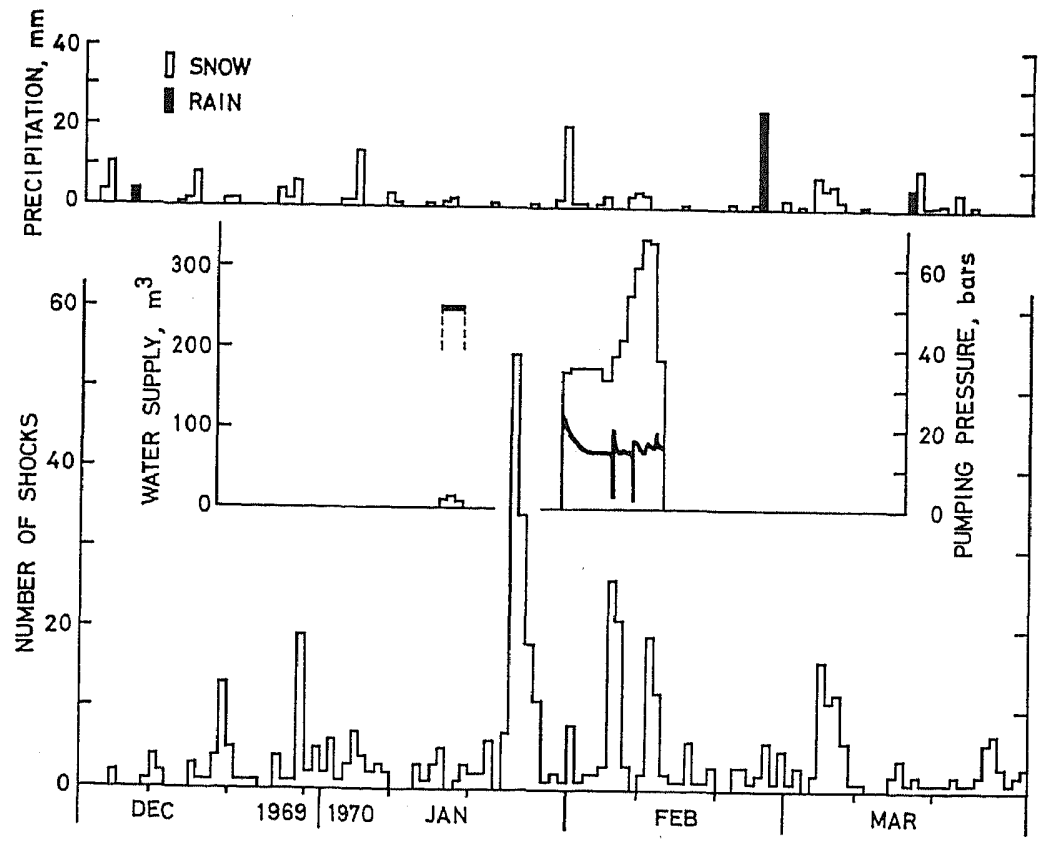

Fig. 3. Top: Precipitation at Nagano City, ten kilometers north of Matsushiro Town. Middle: Volume of the water injected (histogram) and the pumping pressure (thick curues). Bottom: Daily number of the shocks which occurred in the area of water effect. 
increases of pressure in the well with time lags of 9.3-4.8 days. The lag shows a tendency to become shorter with respect to time. Another increase in earthquake frequency on March 5 happened to appear on the 8th day from February 25 when there was an unusually heavy rainfall. Such an apparent correlation is also found between a rainfall on March 16 and a rise in earthquake frequency on March 26 (time lag of 10 days).

\subsection{Hypocentral distribution of earthquakes}

Figure 4 illustrates the hypocentral distribution of shocks which occurred in the area of water effect, dividing the whole period of the observation into three successive stages; (a) 55 days from December 1, 1969 to January 24, 1970 , (b) 44 days from January 25 to March 9, and (c) 22 days from March 10 to 31 . Daily frequency of the shocks for those stages was 2.5, 7.0 and 1.9 on the average, respectively. The stage (b) includes notable activities following the water injection mentioned above. The other stages, on the other hand, represent the periods of ordinary seismicity before and after the effect of the injection.

For the stage (b), the vertical profile of the hypocentral distribution shows peculiar features in contrast with the others. Occurrence of earth-

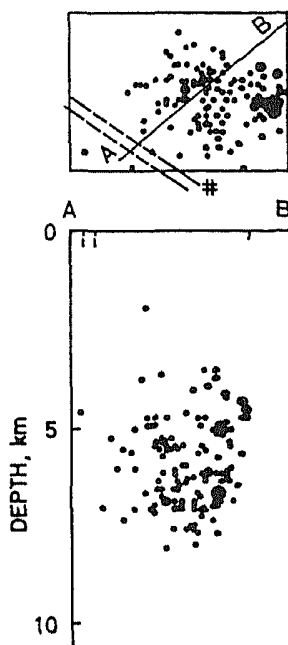

(a)

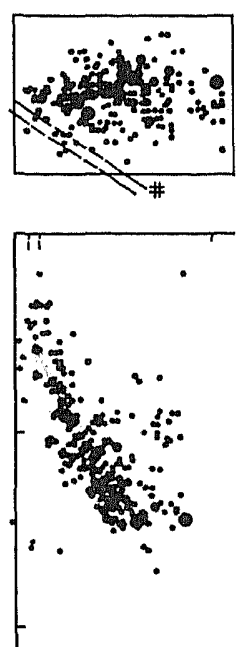

(b)

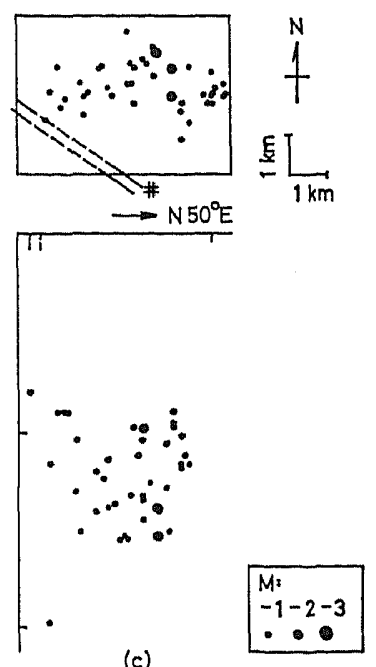

(c)

Fig. 4. Horizontal (top) and vertical (bottom) distribution of the earthquakes which occured in the area of water effect for the period of (a) 55 days from December 1 to January 24, (b) 44 days from January 25 to March 9 and (c) 22 days from March 10 to 31 . The foci of the bottom maps are projected on a vertical plane through $\mathrm{AB}$ trending $N 50^{\circ} \mathrm{E}$. Broken lines indicate the supposed surface trace of the Matsushiro earthquake fault. Location of the well is also shown by parallel crosses. 
quakes shallower than $3.5 \mathrm{~km}$ distinguishes the stage (b) from the other ones. Moreover, the foci in that stage showed a tendency to be clustered along a dipping plane which extends beneath the supposed surface trace of the Matsushiro fault. The seismic plane dips to $\mathrm{N} 50^{\circ} \mathrm{E}$ by about $65^{\circ}$ on the average, though its shallower part seems much steeper.

It is most probable that the shape of the fault plane was illuminated by seismic foci. The Matsushiro earthquake fault is, therefore, supposed to reach the depth of $8 \mathrm{~km}$ and be dipped to the northeastern side. This geometry of the fault reasonably accounts for the peculiar curving of the borehole. Small discrepancy between the strike of the seismic plane and that of the main part of the fault may reflect rightward warping of the fault trace, which has sometimes been observed near the ends of left-lateral faults (MATsudA, 1967).

For the stages (a) and (c), we could not find such a systematic arrangement of hypocenters as was found for the stage (b). However, it is noteworthy that most of the foci in those stages were distributed in the upper block of the fault.

Downward migration of the foci, as is shown in Fig. 5, is another peculiar feature of the stage (b), especially for the seismic sequence following the first injection.

In order to check the reliability of the computed hypocenters, seismic signals from small explosions at the boring site were analysed in the same way as for natural events. All the computed foci were located within $0.5 \mathrm{~km}$ of the well in spite of poor quality of the seismograms. Absolute accuracy in depths may be a little worse than that in epicenters. However, relative accuracy in the hypocenter location between arbitrarily chosen earthquakes is expected much better.

\subsection{Frequency distribution of amplitudes}

Frequency distribution of maximum trace amplitudes at Hoshina station is shown in Fig. 6 for the stages (a), (b) and (c). Corresponding values of

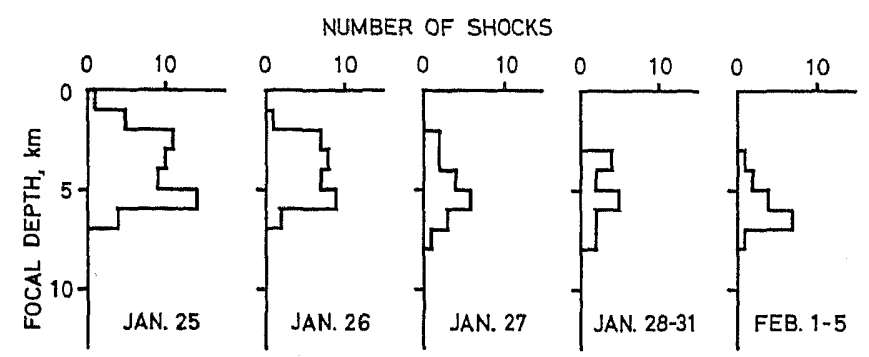

Fig. 5. Change in the depth of earthquake foci with respect to time during the period from January 25 to February 5. 


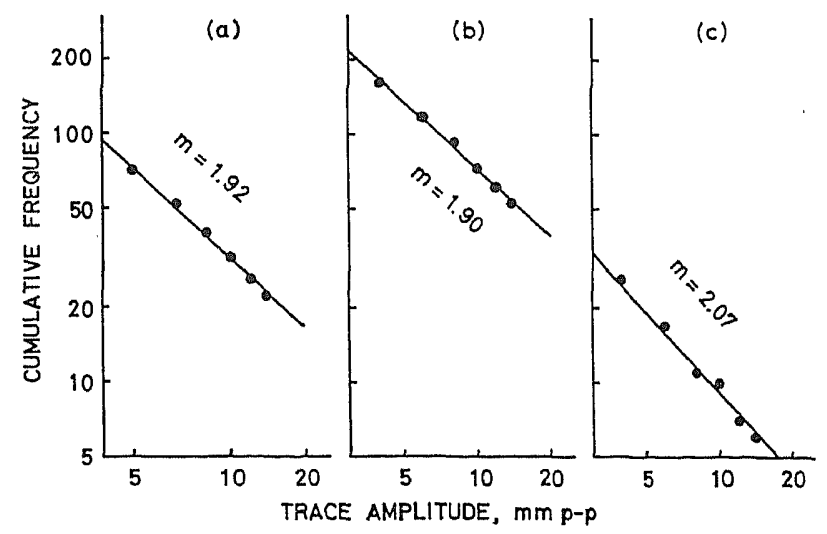

Fig. 6. Frequency distribution of the maximum trace amplitudes at Hoshina. The periods (a), (b) and (c) correspond to those defined in Fig. 4.

Ishimoto-Iida's coefficient, $m$, calculated by the formula of UTsU (1965), were $1.92,1.90$ and 2.07 , respectively. Significant difference was not found among those values. The value of $m$ is supposed to indicate the degree of the structural nonuniformity such as degree of heterogeneity and density of cracks in the medium (Mogr, 1967). It seems that the earthquakes associated with the present water injection had not brought noticeable fracturing to the medium concerned.

\subsection{Fault-plane solution}

Focal mechanisms of the Matsushiro swarm earthquakes were minutely investigated by ICHIKAWA (1969). The solutions were of typical strike-slip with the maximum pressure axes in east-west direction, which were harmonious with the pattern of the crustal deformation during the swarm. The null axes were estimated to be nearly vertical, but it seems that the estimated angles are somewhat ambiguous due to insufficient data of very near stations.

Figure 7(a) gives push-pull distribution of initial motions of a felt earthquake with magnitude 2.8 on January 25 . It was the largest shock which occurred in the area of water effect during the period of our observation. The distribution is compatible with a left-lateral slip of the Matsushiro earthquake fault as represented in Fig. 7(a). The nodal lines are described under the assumption that the fault plane of which strike is $N 55^{\circ} \mathrm{W}$ dips to the northeastern side by $70^{\circ}$. Figure 7(b) shows that such a fault plane solution holds good for smaller earthquakes down to 0.8 in magnitude. Of course, uniqueness of the present solution is questionable because of the insufficient number of stations. We can, however, safely conclude from Fig. 7 that any alternative solutions may not substantially differ from the present one.

Our fault plane solution agrees well with those of the ordinary Matsu- 
JAN. 25, $1970 \quad M=2.8$

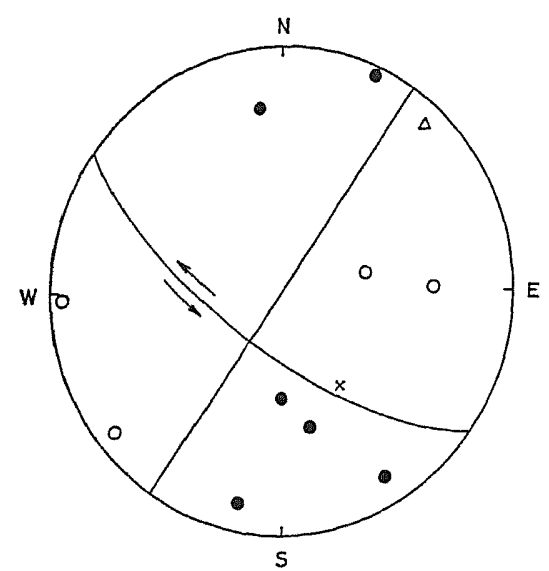

(a)

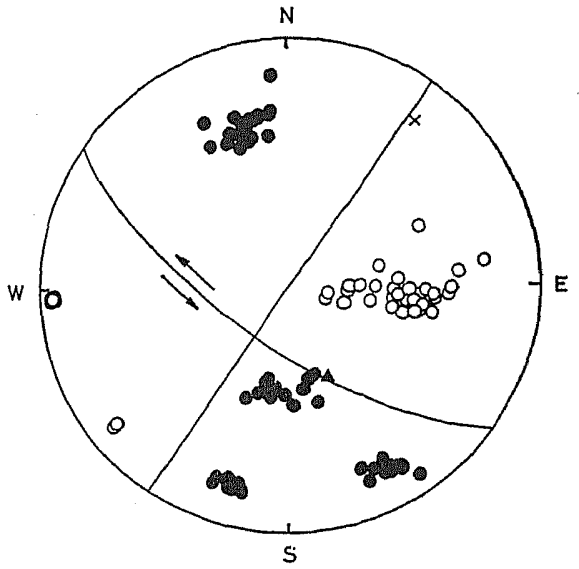

(b)

Fig. 7. Equal area projection (upper hemisphere) of the seismic radiation pattern for (a) the earthquake on January 25 , and (b) the smaller earthquakes. For the latter case, data of a number of earthquakes with magnitude down to 0.8 are superposed on the same map. Solid and open circles indicate compressional, and dilatational initial motion, and cross marks are for equivocal motion. Circles are replaced by triangles where the polarity is not highly reliable. The illustrated nodal lines correspond to a left-lateral slip of the Matsushiro earthquake fault of which dip direction and dip angle are $\mathrm{N} 35^{\circ} \mathrm{E}$ and $70^{\circ}$, respectively.

shiro earthquakes studied by ICHIKAWA (1969) within unavoidable errors in the solutions. It seems that the earthquakes under the effect of the water injection were generated by the stresses which were universal in the Matsushiro area. It was also pointed out by Ichikawa that the mechanisms of the Matsushiro earthquakes were in good agreement with those of shallow earthquakes which had occurred in the northern part of central Japan in the past.

\section{Estimasion of Permeability}

The peculiar features of the seismic activity discussed in the previous section are consistently explained by the concept that the pressure pulses caused by the water injection propagated through the Matsushiro fault and triggered the earthquakes. Estimation of permeability is indispensable to ascertain the reality of such a process. In the following discussions, the fault is assumed to be a vertical half plane for simplicity of treatment.

According to DE WIEST (1966), two dimensional flow of groundwater through a vertical porous medium is expressed by the equation

$$
\frac{\partial H}{\partial t}=a\left(\frac{\partial^{2} H}{\partial x^{2}}+\frac{\partial^{2} H}{\partial z^{2}}+\delta \frac{\partial H}{\partial z}\right),
$$


where $t$ is time, and $x$ and $z$ are Cartesian coordinates fixed on the fault plane as shown in Fig. 8. Hydraulic head, $H$ is related with water pressure $P$ as follows:

$$
H=-z+\frac{1}{g} \int_{0}^{P} \frac{\mathrm{d} P}{\rho},
$$

where $g$ is acceleration of gravity and $\rho$ is density of water. The constants, $a$ and $\delta$ are

$$
a=k\left[\mu\left\{(1-n) \beta_{\mathrm{s}}+n \beta_{l}\right\}\right]^{-1},
$$

and

$$
\delta=2 \rho g \beta_{l},
$$

where $k$ is intrinsic permeability, $\mu$ is fluid viscosity, $n$ is porocity, $\beta_{s}$ is compressibility of solid matrix and $\beta_{l}$ is that of water. The value of $\delta$ is as small as $6 \times 10^{-3} \mathrm{~km}^{-1}$ because $\beta_{l} \approx 3 \times 10^{-5} \mathrm{bar}^{-1}$. Neglecting $\delta$, we obtain from (1)

$$
\frac{\partial H}{\partial t}=a\left(\frac{\partial^{2} H}{\partial x^{2}}+\frac{\partial^{2} H}{\partial z^{2}}\right)
$$

Fundamental solution of (5) with the initial condition of $\left.H\right|_{t=0}=0$, and the boundary condion of $\left.H\right|_{z=0}=0$ is

$$
H(x, z, t ; \zeta)=\frac{1}{4 \pi a t}\left[\mathrm{e}^{-\left(x^{2}+(z-\zeta)^{2}\right) / 4 a t}-\mathrm{e}^{-\left(x^{2}+(z+\zeta)^{2}\right) / 4 a t}\right],
$$

which represents the development of $H$ field by an instantaneous water supply of unit strength at $x=0, z=\zeta$, and $t=0$. The initial condition settled above will be justified as a first approximation because it corresponds to hydrostatic equilibrium of water pressure by Eq. (2). In our case, water was supplied at a depth of about $1.5 \mathrm{~km}$, that is, at the point $x=0$ and $z=1.5 \mathrm{~km}$.

Figure 9 represents relative variation of water pressure with respect to time at the point $x=3 \mathrm{~km}, z=1.5 \mathrm{~km}$, where unusual seismic activity seems to be initiated. It will be reasonable to consider that the peaks of pressure increase should appear between the initiation and the termination of the seismic

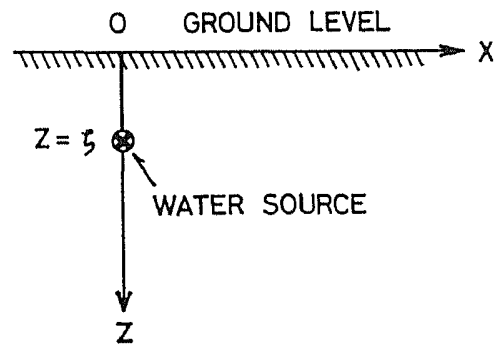

Fig. 8. Coordinate system employed for the present discussion. 


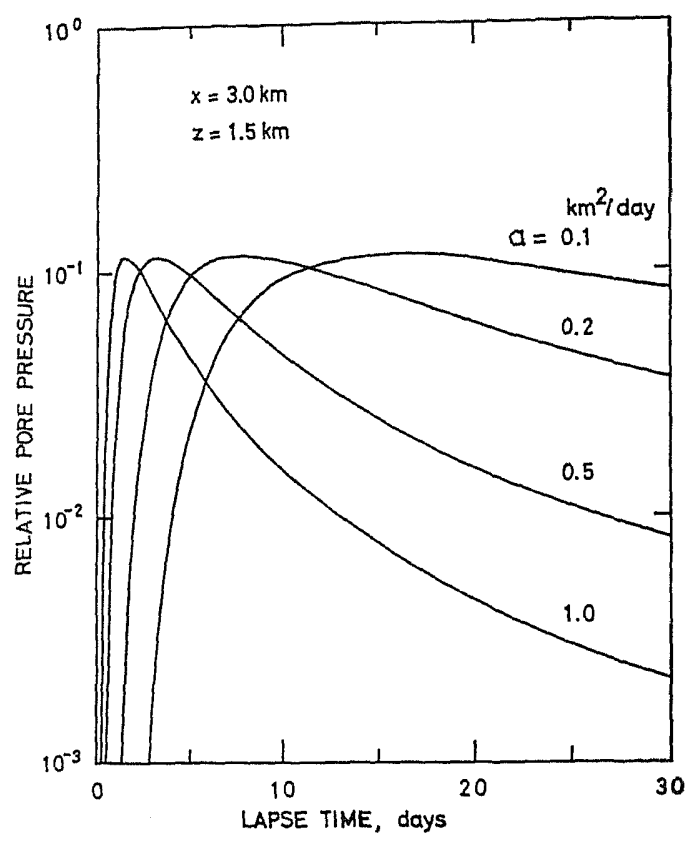

Fig. 9. Theoretical curves of change in the relative pore water pressure at the point $x=3 \mathrm{~km}$ and $z=1.5 \mathrm{~km}$. The value of $4 \pi H$ is plotted against lapse time following Eq. (6).

activities associated with the water injection, that is roughly estimated from Fig. 3 as between 5 and 15 days after the start of injection. Corresponding values of $a$ are estimated to be $0.3-0.1 \mathrm{~km}^{2} /$ day from Fig. 9. Substituting $\mu=5 \times 10^{-3}$ poise, $n=10^{-2}-10^{-1}, \beta_{s}=10^{-6}$ bar $^{-1}, \beta_{l}=3 \times 10^{-5}$ bar ${ }^{-1}$ into (3), $k$ results in $0.01-0.1$ darcy $\left(1\right.$ darcy $\left.\approx 10^{-8} \mathrm{~cm}^{2}\right)$.

Those values are intermediate between the value $0.35 \times 10^{-7}$ darcy for laboratory specimens of granite at an effective confining pressure of 1000 bars (BRACE et al., 1968) and 1 darcy for fractured and jointed rocks (Nur and BOOKER, 1972), and close to the latter. The time lags observed in the present case at Matsushiro are, therefore, reasonably attributed to permeation of water through the Matsushiro earthquake fault. This result seems to affirm the causal relation between the water injection and the seismic activity.

\section{Conclusions}

Following a water injection into a deep well at Matsushiro, a series of microearthquakes occurred at shallow depths two to four kilometers distant from the well. The seismic activity was distinguished from other background activities in the surrounding area by some peculiar features: 
1) Abrupt increases in daily number of the shocks followed the increases in water pressure in the deep well with time lags of 9.3-4.8 days.

2) The hypocenters tended to be distributed along a dipping plane which most probably coincides with the Matsushiro earthquake fault. Such a systematic distribution of the foci vanished in the later stage when the seismic activity subsided to a normal level.

3) The earthquekes were initially very shallow in depth, and migrated to deeper part with respect to time.

Those time and space correlations between the water injection and the seismic activity are consistently explained by the concept that a part of the supplied water permeated through the Matsushiro earthquake fault and excited the activity. It is considered that the increases in pore water pressure reduced the strength of the rocks and resulted in premature releases of elastic strain of tectonic origin as in the case of the Denver earthquakes. The following important findings demonstrate the validity of such a physical mechanism.

1) The water injection did not revive any seismic activities in the initial swarm region of the Matsushiro earthquakes which is supposed to have been completely fractured during the earthquake swarm and not to bear further accumulation of elastic strain.

2) No differences were found between the fault-plane solutions for the the earthquakes associated with the water injection and those for the ordinary Matsushiro earthquakes.

3) Intrinsic permeability through the Matsushiro earthquake fault was estimated as $0.01-0.1$ darcy, which are reasonable values for fractured rocks.

The author is greately indebted to Dr. Takahiro Hagiwara for his helpful advice during the course of this study. He also wishes to thank the stuff of the Hokushin Microearthquake Obervatory for their assistance in the field observation. Additional seismographic data and valuable informations were obtained through the kindness of Dr. Hiroshi Takahashi and Mr. Hiroyoshi Suzuki of the National Research Center for Disaster Prevention and Mr. Keiji Aihara of the Mastushiro Seismological Observatory. Thanks are also due to Dr. Tetsuo Santo of the International Institute of Seismology and Earthquake Engineering for critical reading of the manuscript.

\section{REFERENCES}

Asano, S., S. Kubota, H. Okada, M. Nogoshi, H. Suzuki, K. Ichikawa and H. WataNABE, Underground structure in the Matsushiro earthquake swarm area as derived from explosion seismic data, Special Rep., Geol. Survey Japan, 5, 165-201, 1969.

Brace, W. F., J. B. Walsh and W. T. Frangos, Permeability of granite under high pressure, J. Geophys. Res., 73, 2225-2236, 1968.

BRACE, W. F., Laboratory studies of stick-slip and their application to earthquakes, Tectonophys., 14, 189-200, 1972.

DE Wrest, R. J. M., On the storage coefficient and the equations of groundwater flow, $J$. Geophys. Res., 71, 1117-1122, 1966. 
Evans, D. M., The Denver area earthquakes and the Rocky Mountain Arsenal disposal well, and Mountain Geologist, 3, 23-36, 1966.

Gibbs, J. F., J. H. Healy, C. B. Raleigh and J. Coakley, Seismicity in the Rangely, Colorado area: 1962-1970, Bull. Seism. Soc. Amer., 63, 1557-1570, 1973.

Hagiwara, T. and T. IWATA, Summary of the seismographic observation of Matsushiro swarm earthquakes, Bull. Earthq. Res. Inst., 46, 485-515, 1968.

Healy, J. H., W. W. Rubey, D. T. Griggs and C. B. Raleigh, The Denver earthquakes, Science, 161, 1301-1310, 1968.

Healy, J. H., W. H. K. Lee, L. C. Pakiser, C. B. Raleigh and M. D. Wood, Prospects for earthquake prediction and control, Tectonophys., 14, 319-332, 1972.

Hollister, J. C. and R. J. Weimer (ed.), Geophysical and geological studies of the relationships between the Denver earthquakes and the Rocky Mountain Arsenal well, Quaterly, Colorado School Mines, 63 (1), 1-251, 1968.

HUbBert, M. K. and W. W. Rubey, Role of fluid pressure in mechanics of overthrust faulting, 1. Mechanics of fluid-filled porous solids and its application to overthrust faulting, Bull. Geol. Soc. Amer., 70, 115-166, 1959.

IchIKAwa, M., Matsushiro earthquake swarm, Geophys. Mag., 34, 307-331, 1969.

Matsuda, T., Geological studies on earthquake phenomena, Zisin, Ser II, Special Issue, 230235, 1967 (in Japanese).

Mogr, K., Earthquakes and fractures, Tectonophys., 5, 35-55, 1967.

NAKAMURA, K. and Y. Tsunershi, Ground cracks at Matsushiro probably of underlying strike-slip fault origin, I-Preliminary report, Bull. Earthq. Res. Inst., 44, 1371-1384, 1966.

NAKAmURA, K. and Y. Tsuneishi, Ground cracks at Matsushiro probably of underlying strike-slip fault origin, II-The Matsushiro earthquake fault, Bull. Earthq. Res. Inst., 45, 417-471, 1967.

NuR, A., Dilatancy, pore fluids, and premonitory variations of $t_{s} / t_{p}$ travel times, Bull. Seism. Soc. Amer., 62, 1217-1222, 1972.

Nur, A. and J. R. Booker, Aftershocks caused by pore fluid flow ?, Science, 175, 885-887, 1972.

Pakiser, L. C., J. P. Eaton, J. H. Healy and C. B. Raleigh, Earthquake pediction and control, Science, 166, 1467-1474, 1969.

RотнÉ, J. P., Seismes artificiels, Tectonophys., 9, 215-238, 1970 (in French with English summary).

TAKAhashr, H., Deep boring at Matsushiro, Res. Disaster Prevention, 10, 8-10, 1969 (in Japanese).

TAKASHI, H., Further report on the deep boring at Matsushiro and experiment of water injection, Res. Disaster Prevention, 13, 10-13, 1970 (in Japanese).

Teng, T. L., C. R. Real and T. L. HenYey, Microearthquakes and water flooding in Los Angeles, Bull. Seism. Soc. Amer., 63, 859-875, 1973.

UTsu, T., A method for determining the value of $b$ in a formula $\log n=a-b M$ showing the magnitude-frequency relation for earthquakes, Geophys. Bull., Hokkaido Univ., 13, 99-103, 1965 (in Japanese with English abstract).

WATANABE, H., Determination of earthquake magnitude at regional distance in and near Japan, Zisin, Ser II, 24, 189-200, 1971 (in Japanese with English abstract). 